\title{
Dynamic Behaviour of Thermally Coupled Distillation Arrangements: Effect of the Interconnection Flowrate*
}

\author{
Erick Yair Miranda-Galindo and Juan Gabriel Segovia - Hernández
}

\begin{abstract}
Thermally coupled distillation sequences can provide significant energy savings with respect to the operation of conventional distillation columns. Coupled sequences exhibit a complex structure, with recycle streams, that appear to affect their controllability properties. One potential solution to this problem has been suggested through the operation of complex schemes under conditions that do not provide minimum energy consumption. The basic idea is that if one changes the value of the interconnection flowrate, the control properties might change as well. In this work, we analyze the dynamic behavior of two coupled structures under different operating points, including the one with minimum energy consumption. The control analysis properties are analyzed with the application of the singular value decomposition technique in all frequency domains. The results show that the controllability properties of distillation sequences may change significantly depending on the selected value of interconnection flowrate.
\end{abstract}

KEYWORDS: coupled distillation schemes, control properties, interconnection flowrate

*Author to whom all correspondence should be addressed, e-mail: segovia@quijote.ugto.mx, tel: (52) 4737320006 ext 8142. The authors acknowledge financial support received CONCyTEG and Universidad de Guanajuato, México. 


\section{Introduction}

In the chemical and petrochemical industry, distillation units are the most widely used separation technique for fluid mixtures. The main disadvantage of the distillation is its high energy demand. To improve the energy efficiency of separation processes based on distillation, several strategies have been proposed; one of them calls for the use of complex sequences. For example, thermal coupling has been used in the design of multicomponent distillation systems in order to reduce both energy consumption and capital costs when compared with conventional configurations. Thermally coupled distillation sequences (TCDS) for ternary mixtures have particularly been analyzed with special interest due to the remixing in the intermediate component is reduced and the use of the energy improved (Hernández et al, 2003). Two of the schemes that have received special attention are the systems with side columns: the thermally coupled system with a side rectifier (TCDS-SR, Figure 1) and the thermally coupled system with a side stripper (TCDS-SS, Figure 2). There is a considerable amount of literature on the analysis of the relative advantages of TCDS for ternary separations (Tedder and Rudd, 1978; Annakou and Mizsey, 1996; Triantafyllou and Smith, 1992; Finn, 1993; Hernández and Jiménez, 1996; Hernández and Jiménez, 1999a; Dünnebier and Pantelides, 1999; Yeomans and Grossmann, 2001; Amminudin et al., 2001; Muralikrishna et al., 2002; Hernández et al., 2006, Abad - Zarate et al., 2006; among others). These studies have shown that the thermally coupled configurations are capable of achieving energy savings of up to $30 \%$ in contrast to the conventional direct and indirect distillation sequences for the separation of feeds with low or high content of the intermediate component, and the energy savings depends on the amount of the intermediate component. Also, the thermally coupled distillation sequences for the separation of ternary mixtures, over a wide range of relative volatilities and feed compositions, have been reported to provide a better thermodynamic efficiency than the conventional distillation configurations (Flores et al., 2003; Hernández - Gaona et al., 2005). However, the complex column configurations that can potentially produce larger savings on both energy and capital, have not been implemented extensively in the process industries until recent times (Kaibel et al., 2006), largely because of control concerns (Dünnebier and Pantelides, 1999). Recent research efforts have been conducted to understand the operational properties of thermally coupled configurations. The works of Wolff and Skogestad, 1995; Abdul-Mutalib and Smith, 1998; Hernández and Jiménez, 1999b; Serra et al., 1999; Serra et al., 2001; Jiménez et al., 2001; Segovia - Hernández et al., 2002a; Segovia - Hernández et al., 2002b; Serra et al., 2003; Segovia - Hernández et al., 2004; Segovia Hernández et al., 2005a; Segovia - Hernández et al., 2005b; Segovia - Hernández et al., 2005c; Alcántara - Ávila et al., 2006; Segovia - Hernández et al., 2006a; 
Segovia - Hernández et al., 2006b; Segovia - Hernández et al., 2007a; Segovia Hernández et al., 2007b, among others, have shown that some of these integrated options are controllable, so that the predicted savings in both energy and capital would probably not be obtained at the expense of operational and control problems.

In this work, we analyze the dynamic behavior of two TCDS arrangements under different value of interconnection flowrates, including the one with minimum energy consumption. The control properties are analyzed with the application of the singular value decomposition technique.

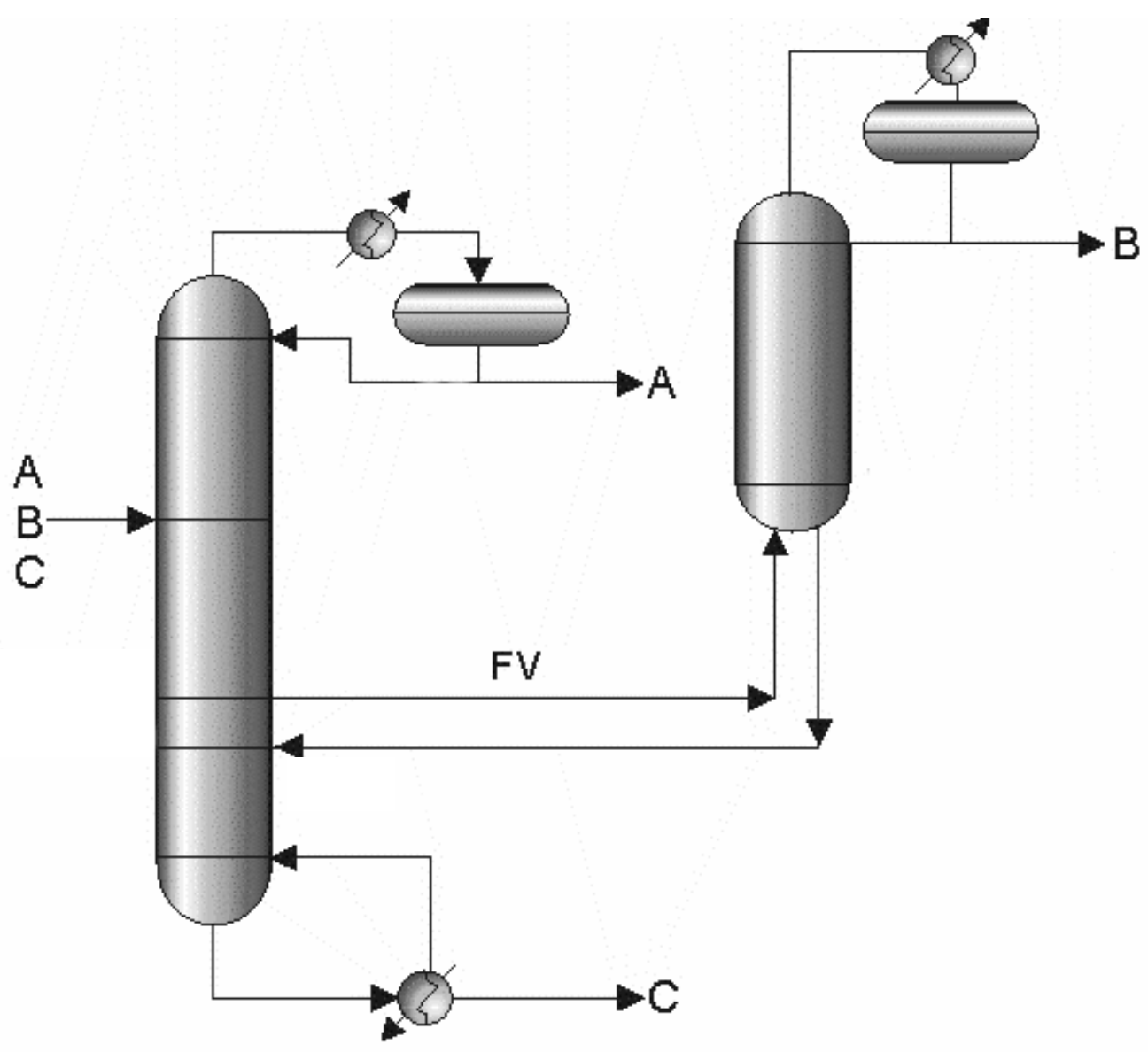

Figure 1. Thermally coupled distillation sequence with side rectifier (TCDS - SR). 


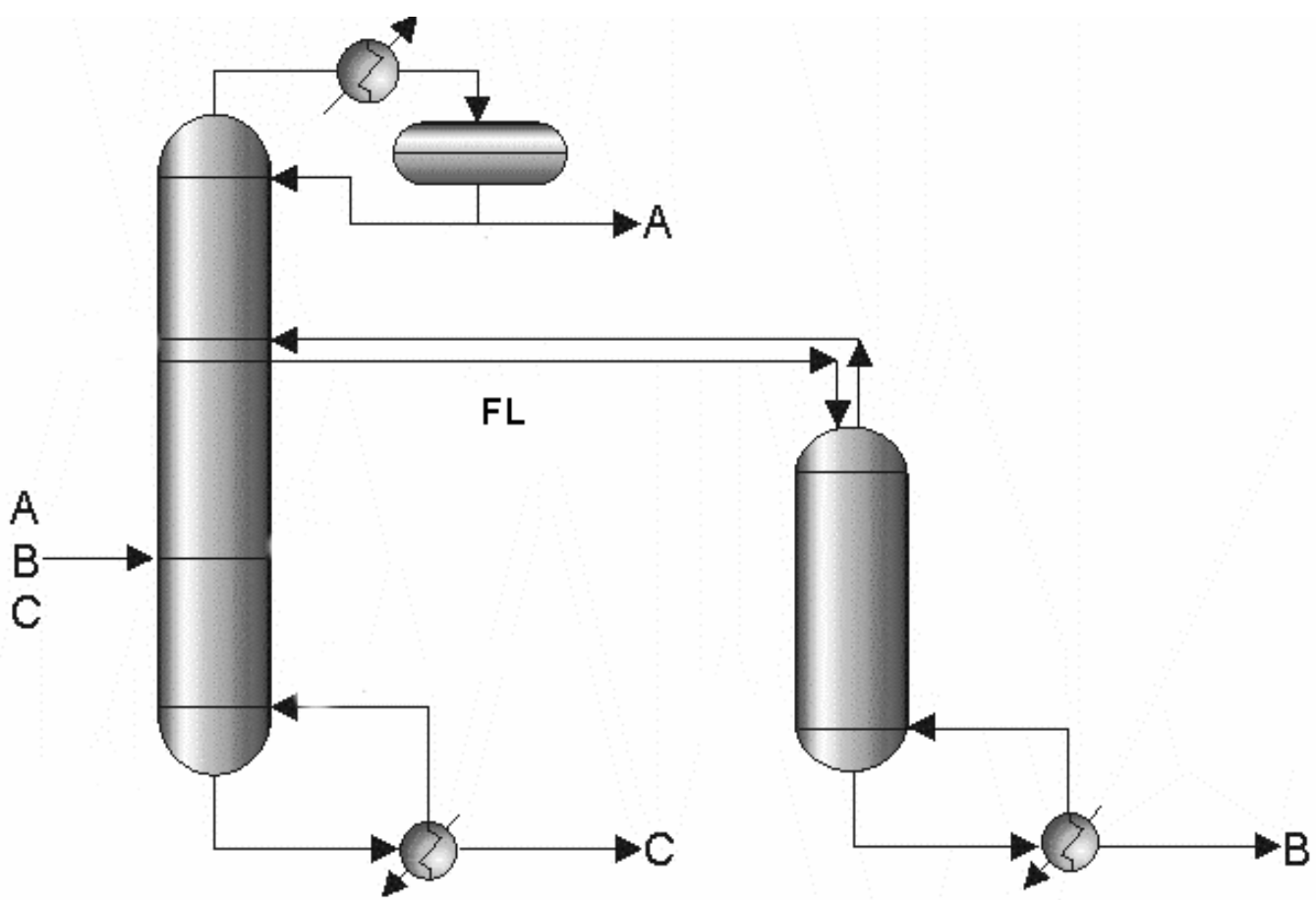

Figure 2 . Thermally coupled distillation sequence with side stripper (TCDS - SS).

\section{Design of Complex Schemes}

The design and optimization strategies for conventional distillation sequences involving the separation of ternary mixtures (Figure 3) are well-known. The energy - efficient design methods for TCDS - SR and TCDS - SS schemes are described in Hernández and Jiménez (1996). Basically, preliminary designs of the TCDS options are obtained from the conventional sequences (Figure 3). The TCDS-SR is obtained from the tray arrangements of a direct sequence (Figure 3a) and the TCDS-SS from an indirect sequence (Figure $3 b$ ). The degrees of freedom that remain after design specifications (one degree of freedom for the systems with side columns) were used to obtain the operating conditions under which the integrated designs provide minimum energy consumption. The search procedure provided the optimal values of the interconnecting vapor flowrate (VF) for the TCDS-SR (Figure 1) and the interconnecting liquid flowrate (LF) for the TCDSSS (Figure 2). Rigorous simulations, using the dynamic model developed by Hernández and Jiménez (1996), were conducted to test the designs. The design is successful if it meets the product specifications; otherwise, proper adjustments are 
made in the tray structure or reflux flowrate values until the design specifications are met. The dynamic analysis is then conducted using the validated design with minimum energy consumption for each case.
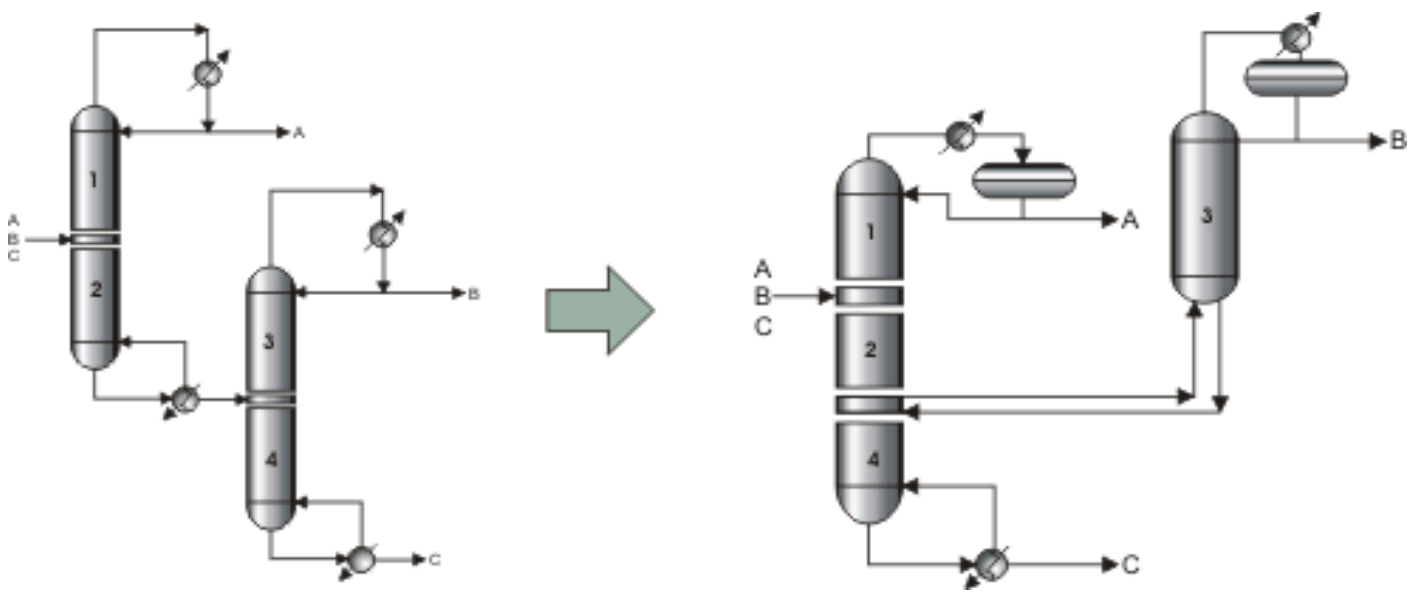

(a)
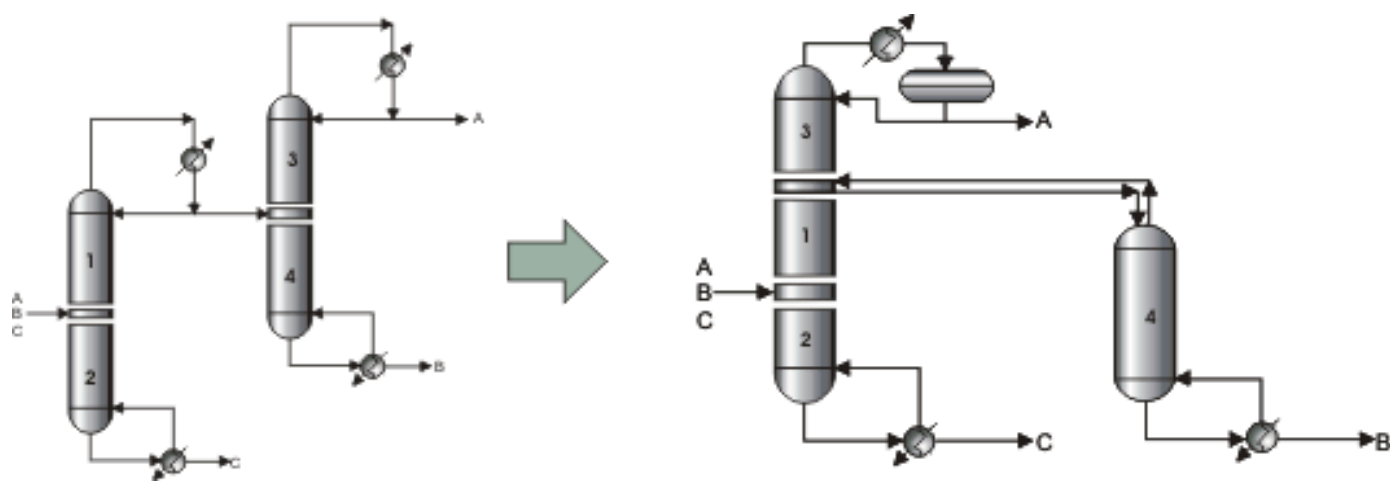

(b)

Figure 3. Rearrangement of the conventional columns into TCDS: (a) system with side rectifier; (b) system with side stripper. 


\section{Singular Value Decomposition (SVD) Study}

As the disturbance in process variables under actual operation conditions are almost inevitable, the prediction of the transient response of a distillation column bears much importance in the sense of the effective control of the separation process (Berber and Karadurmus, 1989). In this work, open loop dynamic responses to set point changes around the assumed operating point were obtained as first step. Transfer function matrices $(\mathrm{G})$ were then collected for each case, and they were subjected to singular value decomposition (SVD). For more details about SVD see Klema and Laub (1980). SVD presents three parameters of interest: the minimum singular value (ọthe maximum singular value $(\sigma)$ and the ratio maximum to minimum singular values, or condition number $(\gamma)$ :

$$
\gamma^{*}=\sigma^{*} / \sigma^{*}
$$

The condition number reflects the sensitivity of the system under uncertainties in process parameters and modeling errors. The minimum singular value is a measure of the invertibility of the system and represents a measure of the potential problems of the system under feedback control. These parameters provide a qualitative assessment of the theoretical control properties of the alternate designs. The systems with higher minimum singular values and lower condition numbers are expected to show the best dynamic performance under feedback control (Klema and Laub, 1980). Such analysis should give some preliminary indication on the control properties of each system (similar analysis has been done by Hernández and Jiménez, 1999b, Segovia - Hernández et al., 2005a and Segovia Hernández et al., 2005c, Segovia - Hernández et al., 2007a, among others).

\section{Cases of study}

Several case studies were chosen to test the effect of the relative volatilities of the feed mixtures. Feed stream with low amounts of the intermediate component (B), where $\mathrm{A}, \mathrm{B}, \mathrm{C}$ equal to $0.4,0.2$, and 0.4 in mole fraction was considered. The effect of relative volatilities was assessed through the ease of separability index (ESI) defined by Tedder and Rudd (1978),

$$
E S I=\frac{\alpha_{A B}}{\alpha_{B C}}
$$

The mixtures analyzed were n-pentane, $n$-hexane and n-heptane (M1; ESI = 1.04); n-butane, isopentane and n-pentane (M2; ESI = 1.86); and isobutane, n- 
butane and $n$-hexane $(\mathrm{M} 3$; ESI $=0.18)$. The feed flowrate was taken as 45.4 $\mathrm{kmol} / \mathrm{hr}$ as saturated liquid, and the specified purities for the product streams were assumed as 98.7, 98 and 98.6 percent for A, B and C respectively. Isobaric conditions were assumed, and the design pressure for each sequence was chosen such all condensers could be operated with cooling water. Since the feed involves a hydrocarbon mixture, the Chao - Seader correlation was used for the prediction of thermodynamic properties for all cases of study. The tray arrangements and some parameters for the TCDS - SR and TCDS - SS after optimization task for the case of study M1 is given in Table 1 and 2.

Table 1. Design Variables for the TCDS - SR for all cases of study.

\begin{tabular}{|c|c|c|c|c|c|c|}
\hline & \multicolumn{2}{|c|}{ M1 } & \multicolumn{2}{|c|}{ M2 } & \multicolumn{2}{|c|}{ M3 } \\
\hline & $\begin{array}{c}\text { Main } \\
\text { Column }\end{array}$ & $\begin{array}{c}\text { Side } \\
\text { Rectifier }\end{array}$ & $\begin{array}{c}\text { Main } \\
\text { Column }\end{array}$ & $\begin{array}{c}\text { Side } \\
\text { Rectifier }\end{array}$ & $\begin{array}{c}\text { Main } \\
\text { Column }\end{array}$ & $\begin{array}{c}\text { Side } \\
\text { Rectifier }\end{array}$ \\
\hline Pressure (atm) & 1.48 & 1.48 & 4.49 & 1.95 & 1.87 & 1.43 \\
\hline Stages & 26 & 10 & 56 & 38 & 68 & 9 \\
\hline Feed Stage & 9 & ----- & 11 & ----- & 32 & ----- \\
\hline $\begin{array}{c}\text { Interconnection } \\
\text { Stage }\end{array}$ & 17 & ----- & 22 & ---- & 61 & ----- \\
\hline $\mathrm{FV}(\mathrm{kmol} / \mathrm{hr})$ & 27.22 & ----- & 112.04 & ----- & 25.4 & ----- \\
\hline Reflux Ratio & 2.31 & 2.26 & 4.31 & 13.865 & 3.505 & 1.51 \\
\hline
\end{tabular}


Table 2. Design Variables for the TCDS - SS for all cases of study.

\begin{tabular}{|c|c|c|c|c|c|c|}
\hline & \multicolumn{2}{|c|}{ M1 } & \multicolumn{2}{|c|}{ M2 } & \multicolumn{2}{|c|}{ M3 } \\
\hline & $\begin{array}{l}\text { Main } \\
\text { Column }\end{array}$ & $\begin{array}{c}\text { Side } \\
\text { Rectifier }\end{array}$ & $\begin{array}{l}\text { Main } \\
\text { Column }\end{array}$ & $\begin{array}{c}\text { Side } \\
\text { Rectifier }\end{array}$ & $\begin{array}{l}\text { Main } \\
\text { Column }\end{array}$ & $\begin{array}{c}\text { Side } \\
\text { Rectifier }\end{array}$ \\
\hline Pressure (atm) & 1.44 & 1.44 & 3.59 & 4.49 & 1.87 & 2.04 \\
\hline Stages & 29 & 8 & 77 & 10 & 50 & 28 \\
\hline Feed Stage & 20 & ----- & 45 & ----- & 42 & ----- \\
\hline $\begin{array}{l}\text { Interconnection } \\
\text { Stage }\end{array}$ & 9 & ---- & 11 & ---- & 32 & ---- \\
\hline $\mathrm{FV}(\mathrm{kmol} / \mathrm{hr})$ & 25.4 & ---- & 27.67 & ----- & 142.88 & ----- \\
\hline Reflux Ratio & 3.505 & ----- & 13.51 & ---- & 10.8 & ---- \\
\hline
\end{tabular}

\section{Results}

The theoretical control properties of thermally coupled distillation sequences were obtained using SVD technique. The set of simulations were analyzed in the optimal operation conditions (optimal reboiler duty) and nonoptimal operation conditions obtained by fixing FL or FV (depending of the arrangement) in different values (remembering that reboiler duty is function of the FL or FV values; see Figures 4 and 5). The SVD technique requires transfer function matrices, which are generated by implementing step changes in the manipulated variables of the optimum design of the distillation sequences and registering the dynamic responses of the three products. After the optimum designs were obtained, open-loop dynamic simulations were obtained in Aspen Dynamics 11. In this work, the reflux flowrate (R) and the reboiler heat duty (Q) were chosen as the manipulated variables. As examples, Tables 3 and 4 show the transfer function matrixes generated by using step changes in the manipulated variables and recording the dynamic behavior of the three product compositions (A, B, and $\mathrm{C}$ ) for DS and TCDS-SR (M1). Serra et al., (1999) have explained that working out 
of the optimal operating conditions, the controllability of the Petlyuk column may improve. Thus, it will be interesting to compare the controllability of the TCDS with side column at nonoptimal conditions. For the TCDS - SR and TCDS - SS several operational conditions are analyzed: the optimal operation (FL or FV are used to optimize the reboiler duty) and some nonoptimal operation values. The reboiler duty and FL or FV values are indicated in Tables $5-6$. Nonoptimal values have a higher reboiler duty than the optimal operation point (Table 5 and 6). To compare the controllability of the different operation values, their controllability indexes are analyzed (minimum singular value and condition number). In the Figures $6-17$, the $\sigma *$ and $\gamma^{*}$ for all cases of study are showed. There are important differences between the column operated at optimal operation and the column operated at nonoptimal condition.

Table 3. Transfer Function Matrix for Direct Sequence (DS, M1).

$$
\begin{aligned}
& \begin{array}{lll}
\text { R1 R2 } & \text { Q }
\end{array}
\end{aligned}
$$

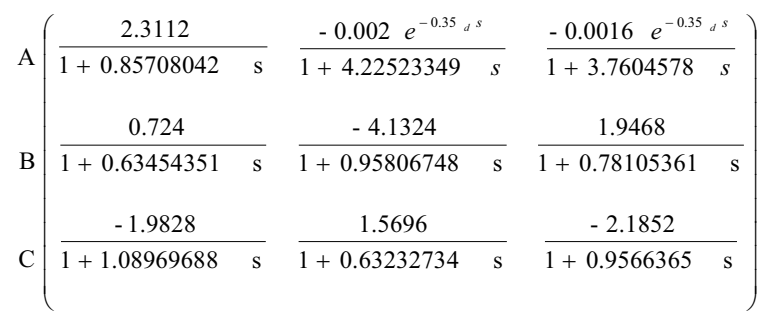

Table 4. Transfer Function Matrix for TCDS - SR (M1) in optimum value of FV.

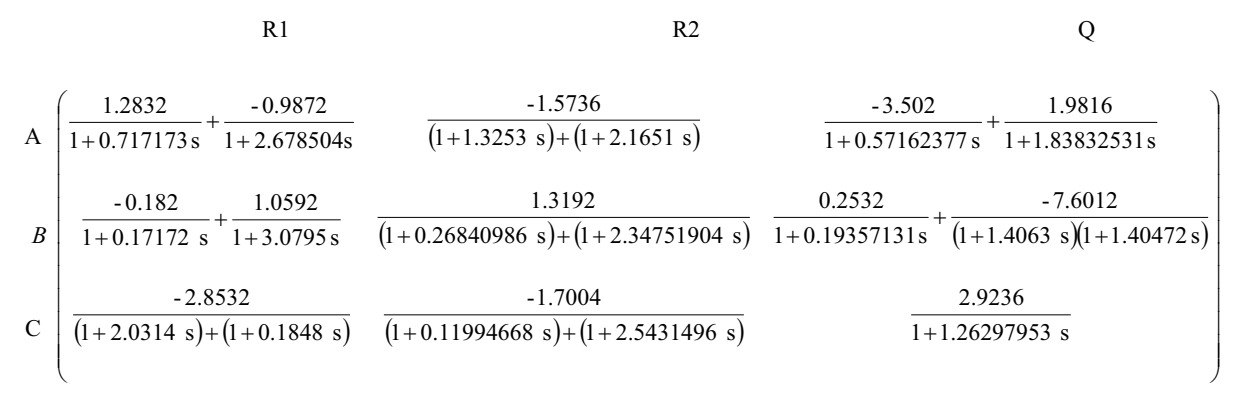


Miranda-Galindo and Segovia - Hernández: Dynamic Behaviour of Thermally Coupled Distillation Arrangements

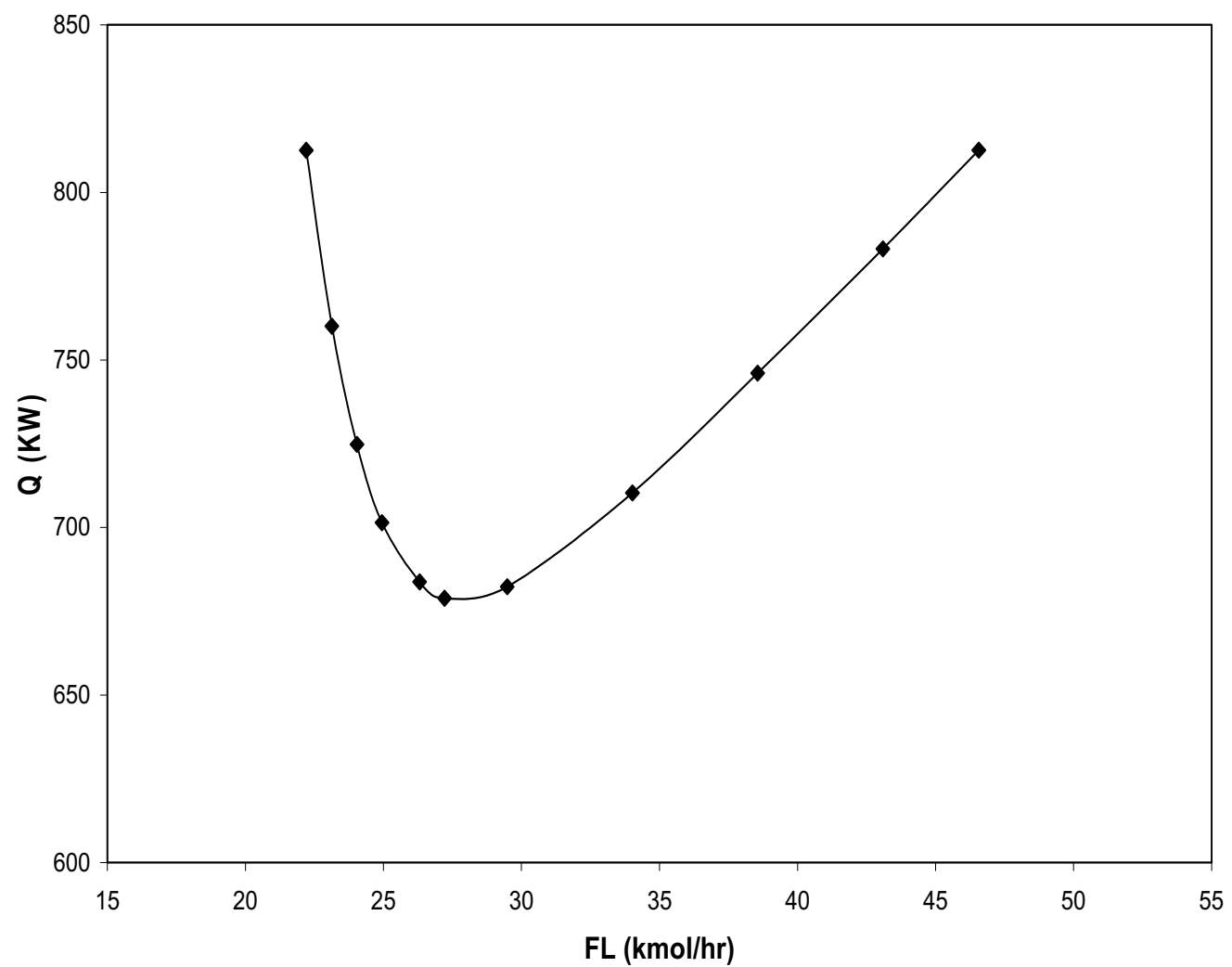

Figure 4. Variation of the interconnection flow with the heat duty of TCDS- SR (M1). 
Chemical Product and Process Modeling, Vol. 3 [2008], Iss. 1, Art. 9

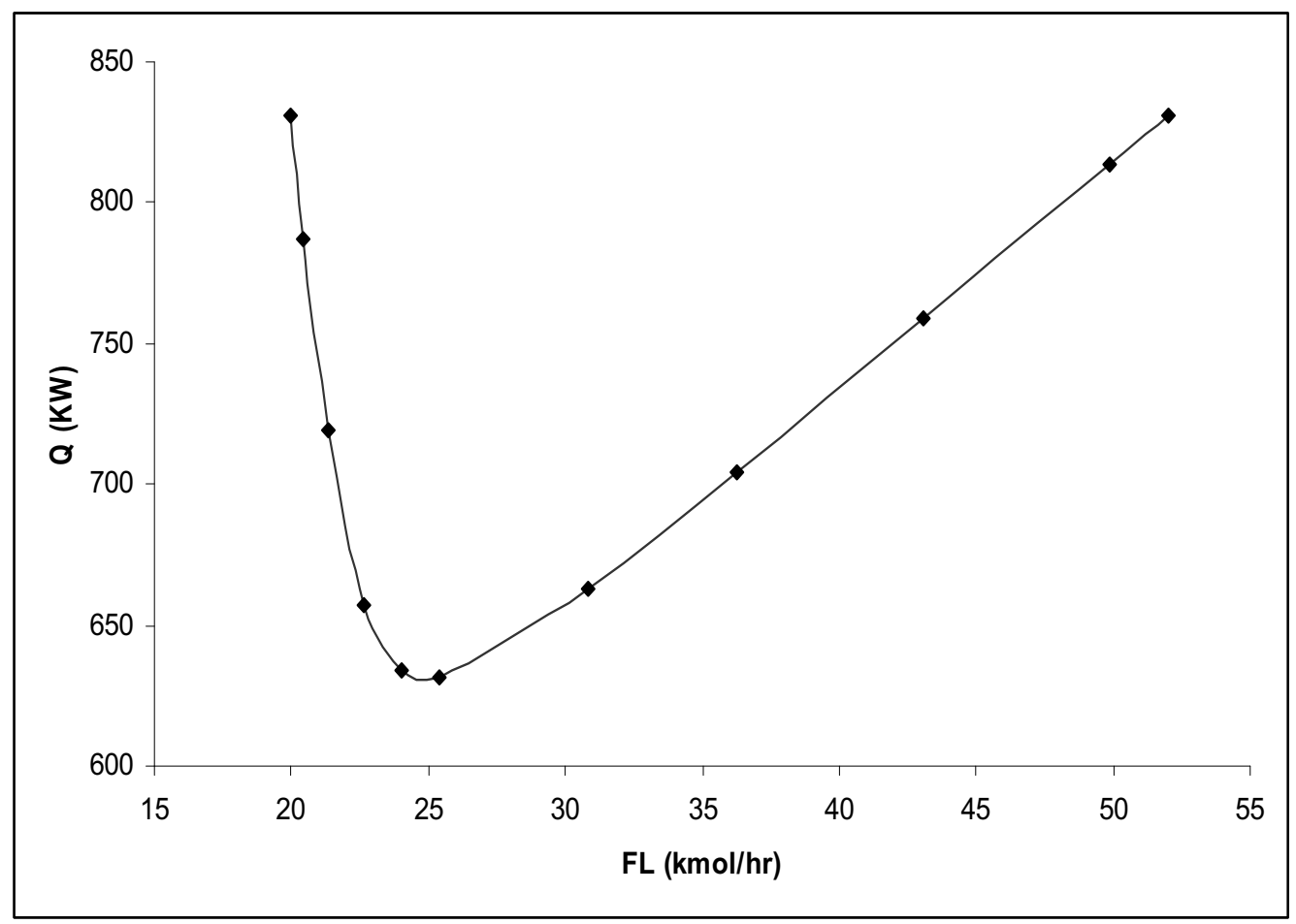

Figure 5. Variation of the interconnection flow with the heat duty of TCDS- SS (M1). 
Table 5. Reboiler duty at different values of FV for TCDS - SR for all cases of study.

\begin{tabular}{|c|c|c|c|c|c|}
\hline \multicolumn{2}{|c|}{ M1 } & \multicolumn{2}{|c|}{ M2 } & \multicolumn{2}{|c|}{ M3 } \\
\hline $\begin{array}{c}\mathrm{FV} \\
(\mathrm{kmol} / \mathrm{hr})\end{array}$ & $\begin{array}{c}\mathrm{Q} \\
(\mathrm{kW})\end{array}$ & $\begin{array}{c}\mathrm{FV} \\
(\mathrm{kmol} / \mathrm{hr})\end{array}$ & $\begin{array}{c}\mathrm{Q} \\
(\mathrm{kW})\end{array}$ & $\begin{array}{c}\mathrm{FV} \\
(\mathrm{kmol} / \mathrm{hr})\end{array}$ & $\begin{array}{c}\mathrm{Q} \\
(\mathrm{kW})\end{array}$ \\
\hline 22.2 & 812.8 & 69.50 & 2447.9 & 19.78 & 1598.0 \\
\hline 23.13 & 760.2 & 78.02 & 1968.9 & 20.41 & 1510.8 \\
\hline 24.04 & 724.9 & 86.64 & 1684.9 & 21.32 & 1453.4 \\
\hline 24.92 & 701.6 & 95.26 & 1506.6 & 22.23 & 1429.1 \\
\hline 26.33 & 683.9 & 103.42 & 1407.8 & 23.14 & 1419.5 \\
\hline $\begin{array}{c}27.22 \\
\text { (optimal } \\
\text { value) }\end{array}$ & 679.1 & $\begin{array}{c}112.04 \\
\text { (optimal } \\
\text { value) }\end{array}$ & 1376.8 & $\begin{array}{c}24.04 \\
\text { (optimal } \\
\text { value) }\end{array}$ & 1417.0 \\
\hline 29.48 & 682.4 & 122.47 & 1412.0 & 33.12 & 1476.4 \\
\hline 34 & 710.4 & 132.45 & 1473.0 & 37.65 & 1516.7 \\
\hline 38.55 & 746.2 & 142.88 & 1544.8 & 42.19 & 1557.7 \\
\hline 43.19 & 783.3 & 158.31 & 1656.8 & 46.73 & 1598.6 \\
\hline 46.57 & 812.8 & 173.27 & 1767.8 & 46.73 & 1598.6 \\
\hline
\end{tabular}


Table 6. Reboiler duty at different values of FL for TCDS - SS for all cases of study.

\begin{tabular}{|c|c|c|c|c|c|}
\hline \multicolumn{2}{|c|}{} & \multicolumn{2}{c|}{ M2 } & \multicolumn{2}{c|}{ M3 } \\
\hline FV & Q & FV & Q & FV & Q \\
$(\mathrm{kmol} / \mathrm{hr})$ & $(\mathrm{kW})$ & $(\mathrm{kmol} / \mathrm{hr})$ & $(\mathrm{kW})$ & $(\mathrm{kmol} / \mathrm{hr})$ & $(\mathrm{kW})$ \\
\hline 19.97 & 830.6 & 19.52 & 1790.4 & 112.96 & 1613.9 \\
\hline 20.42 & 787.3 & 20.87 & 1654.9 & 119.31 & 1544.7 \\
\hline 21.32 & 719.3 & 22.68 & 1574.6 & 125.21 & 1493.6 \\
\hline 22.61 & 657.3 & 24.04 & 1547.6 & 131.11 & 1455.0 \\
\hline 24.04 & 633.9 & 25.86 & 1534.9 & 137.00 & 1427.9 \\
\hline 25.4 & 631.3 & 27.67 & 1531.9 & 142.90 & 1418.8 \\
\hline $\begin{array}{c}\text { optimal } \\
\text { value })\end{array}$ & & $($ optimal & & $($ optimal & \\
\hline 30.84 & 662.7 & 29.94 & 1540.5 & 147.44 & 1424.1 \\
\hline 36.37 & 704.7 & 32.21 & 1552.1 & 151.98 & 1437.9 \\
\hline 43.09 & 758.9 & 34.47 & 1566.5 & 156.97 & 1459.2 \\
\hline 49.95 & 813.7 & 37.65 & 1588.4 & 161.96 & 1484.8 \\
\hline 52 & 830.6 & 40.82 & 1612.3 & 166.95 & 1512.6 \\
\hline
\end{tabular}


Table 7. Energy requirements $(\mathrm{kW})$ for the separation of the ternary mixtures using conventional sequences.

\begin{tabular}{|c|c|c|}
\hline & Direct Sequence & Indirect Sequence \\
\hline M1 & 812.8 & 830.6 \\
\hline M2 & 2447.9 & 1790.4 \\
\hline M3 & 1598.3 & 1730.1 \\
\hline
\end{tabular}

In the case of TCDS - SR (M1), when it is operated at nonoptimal conditions $(\mathrm{FV}=24.04 \mathrm{kmol} / \mathrm{hr}$; see Table 5) its controllability improves. In those nonoptimal conditions, TCDS - SR present highest value of the minimum singular value (Figure 6); therefore, it can be expected that coupled system exhibit better control properties than the sequence, in optimal condition, under feedback control. The results for the condition number show that sequence in the nonoptimal value offer the best value (Figure 7). As a result, it can be expected that thermally coupled distillation system in a different operating condition is better conditioned to the effect of disturbances than the optimal arrangement (in other words, the complex system can eliminate the disturbances better that the conventional arrangements in a non optimal operating condition). As has been explained, the operation in nonoptimal conditions has higher energy consumption than optimal conditions. Consequently when the reboiler duty is increased, the controllability has improved. The reboiler duty is lower than the conventional sequence (Table 7) in the case when the controllability parameters are better than the optimal scheme. Similar results are showed for TCDS - SR (M1) in the Table 5 . 


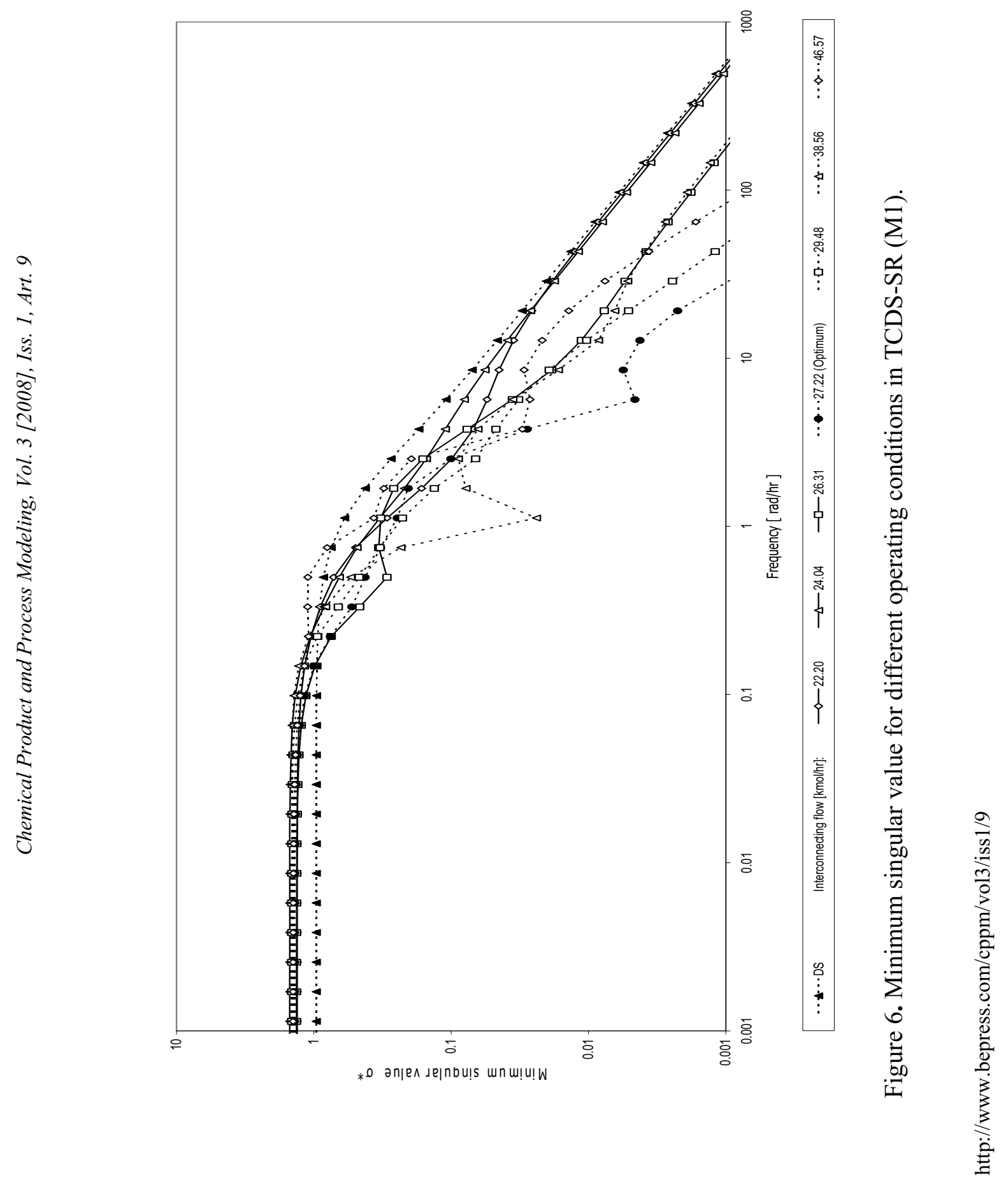




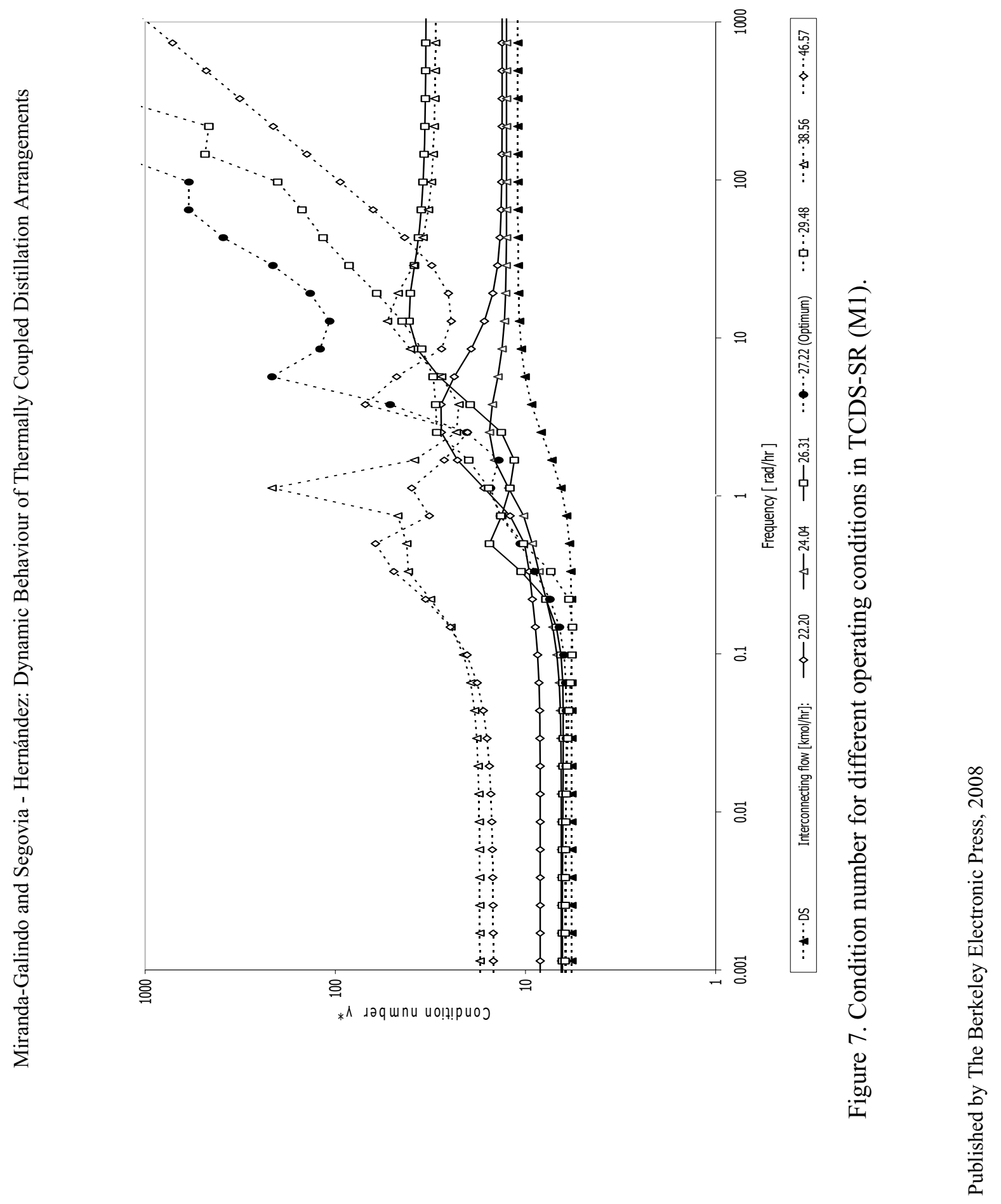




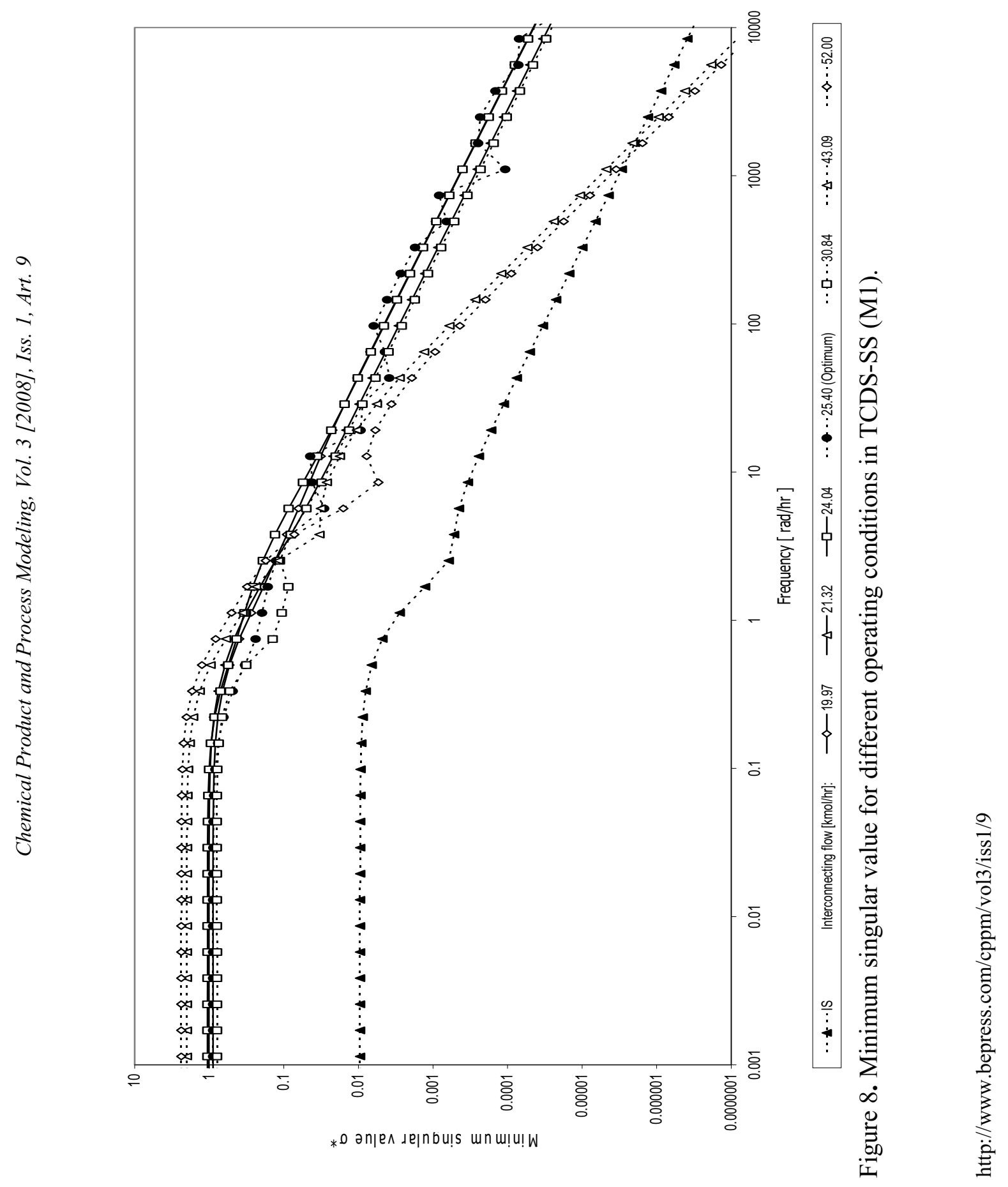




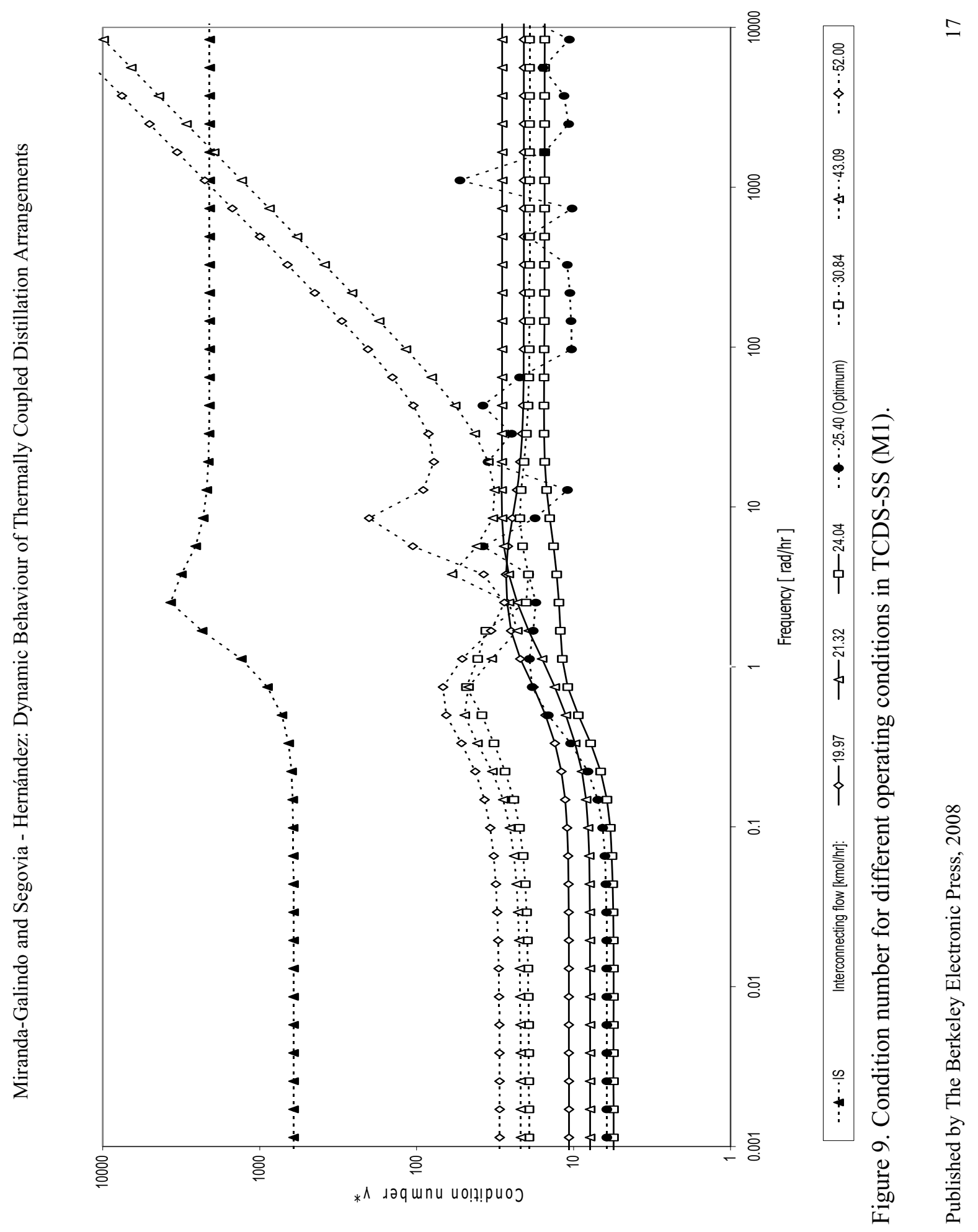




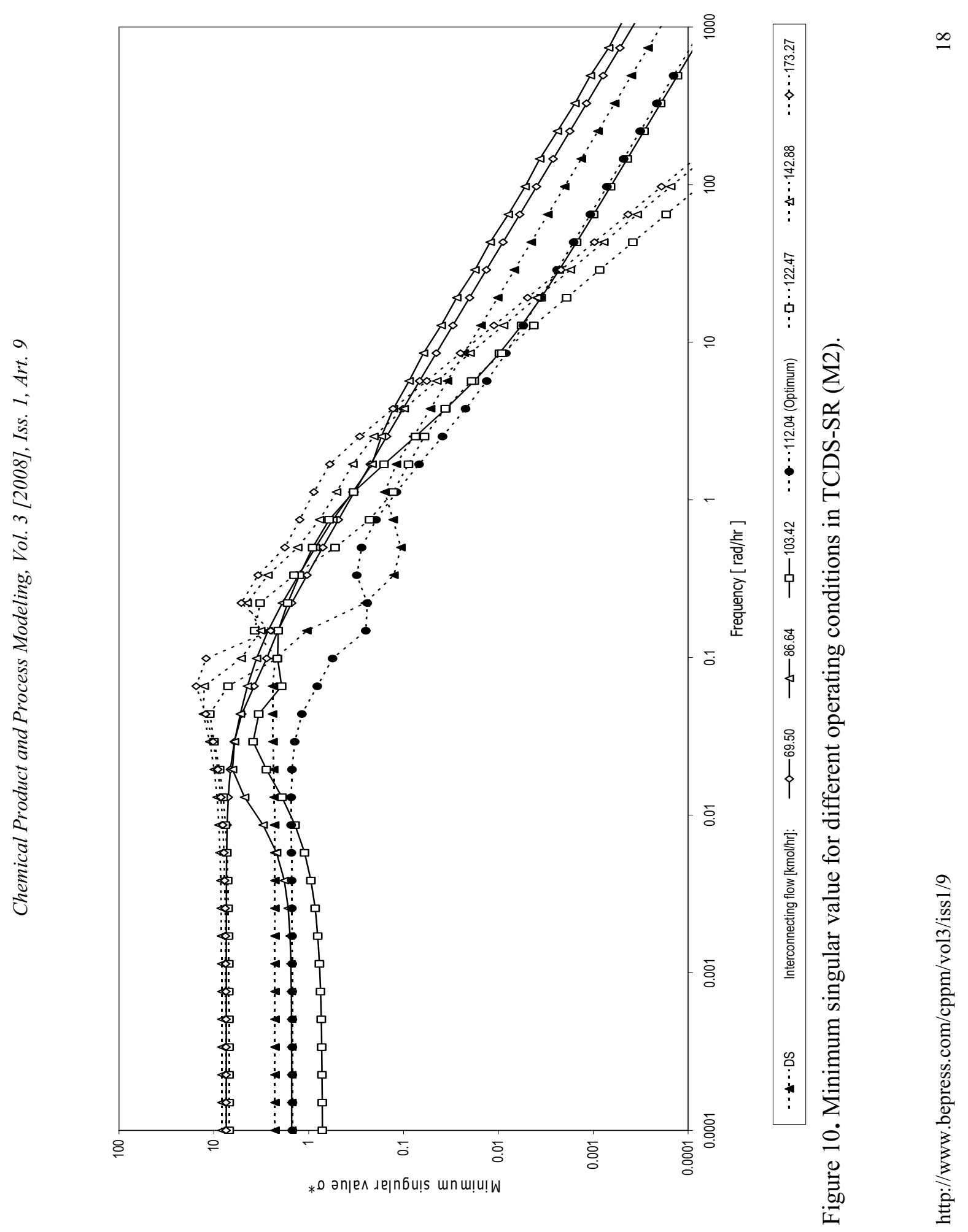




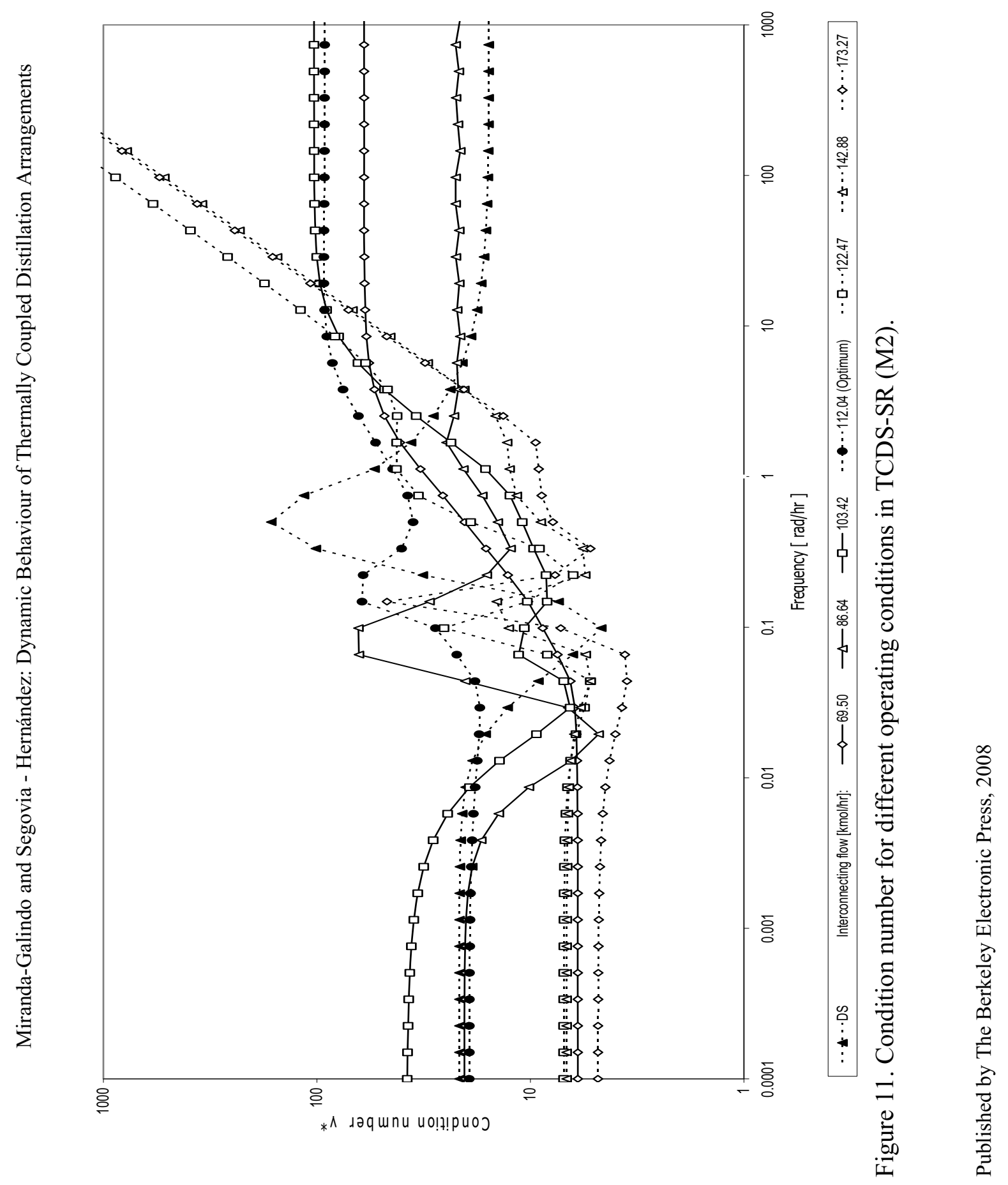




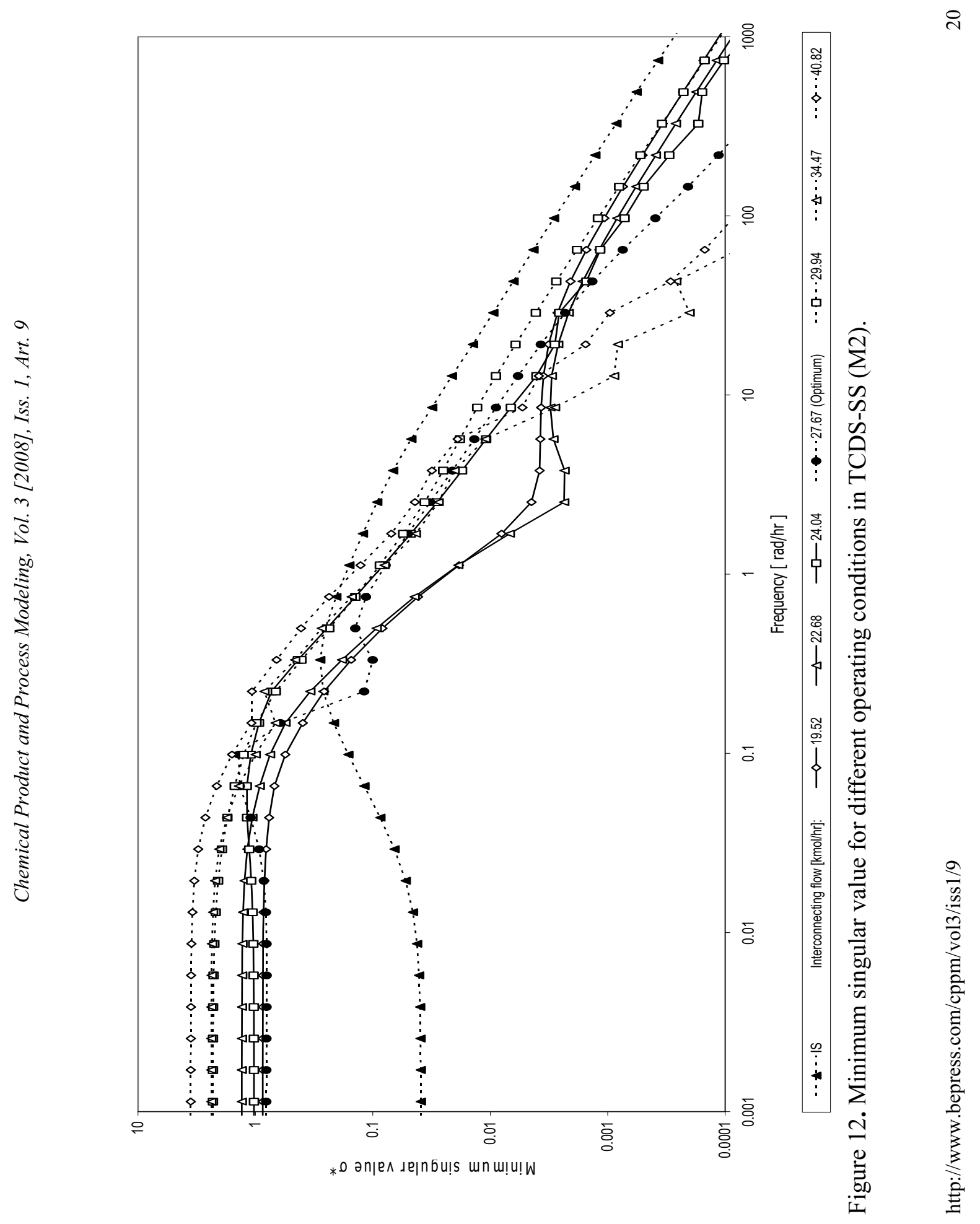




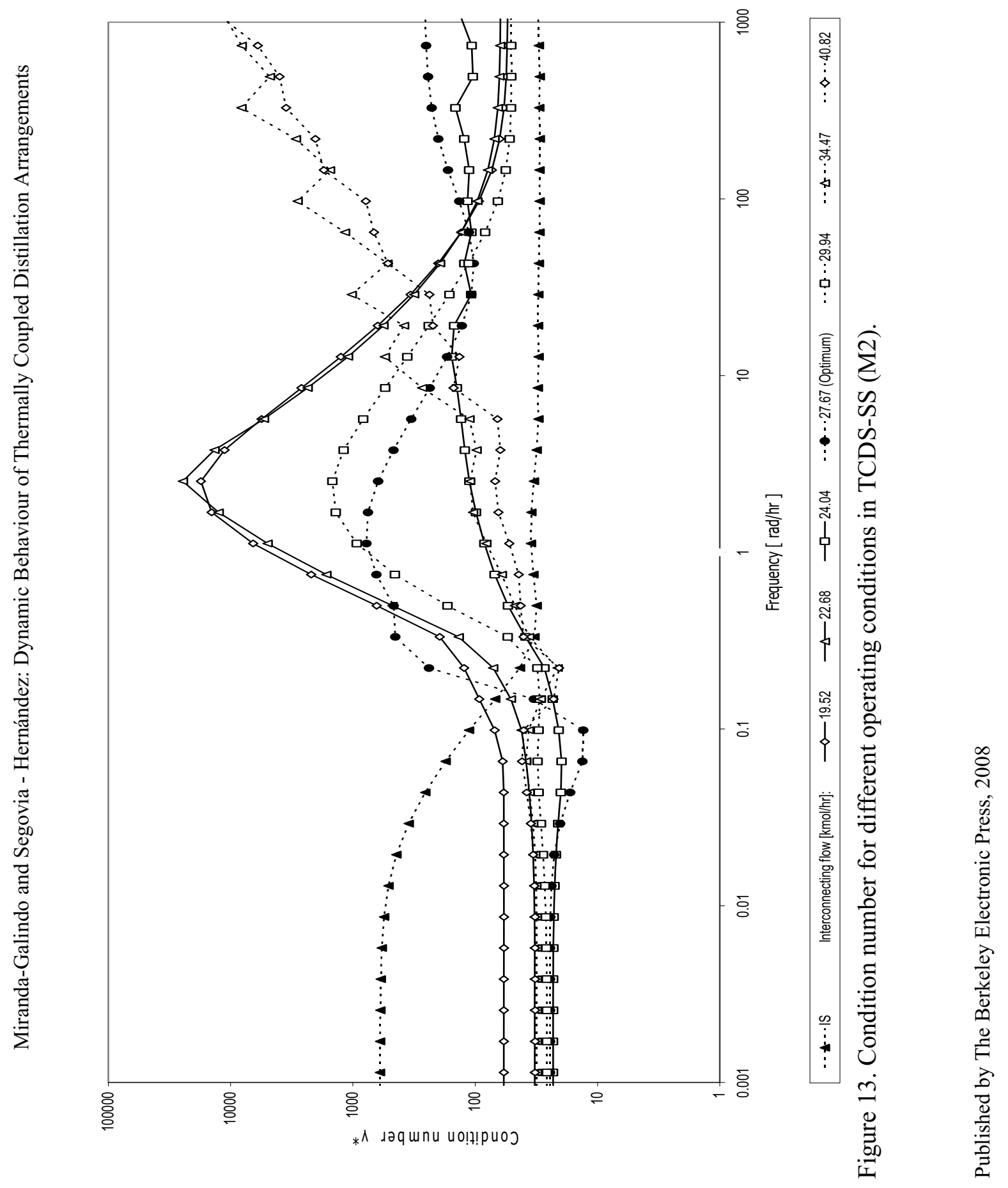




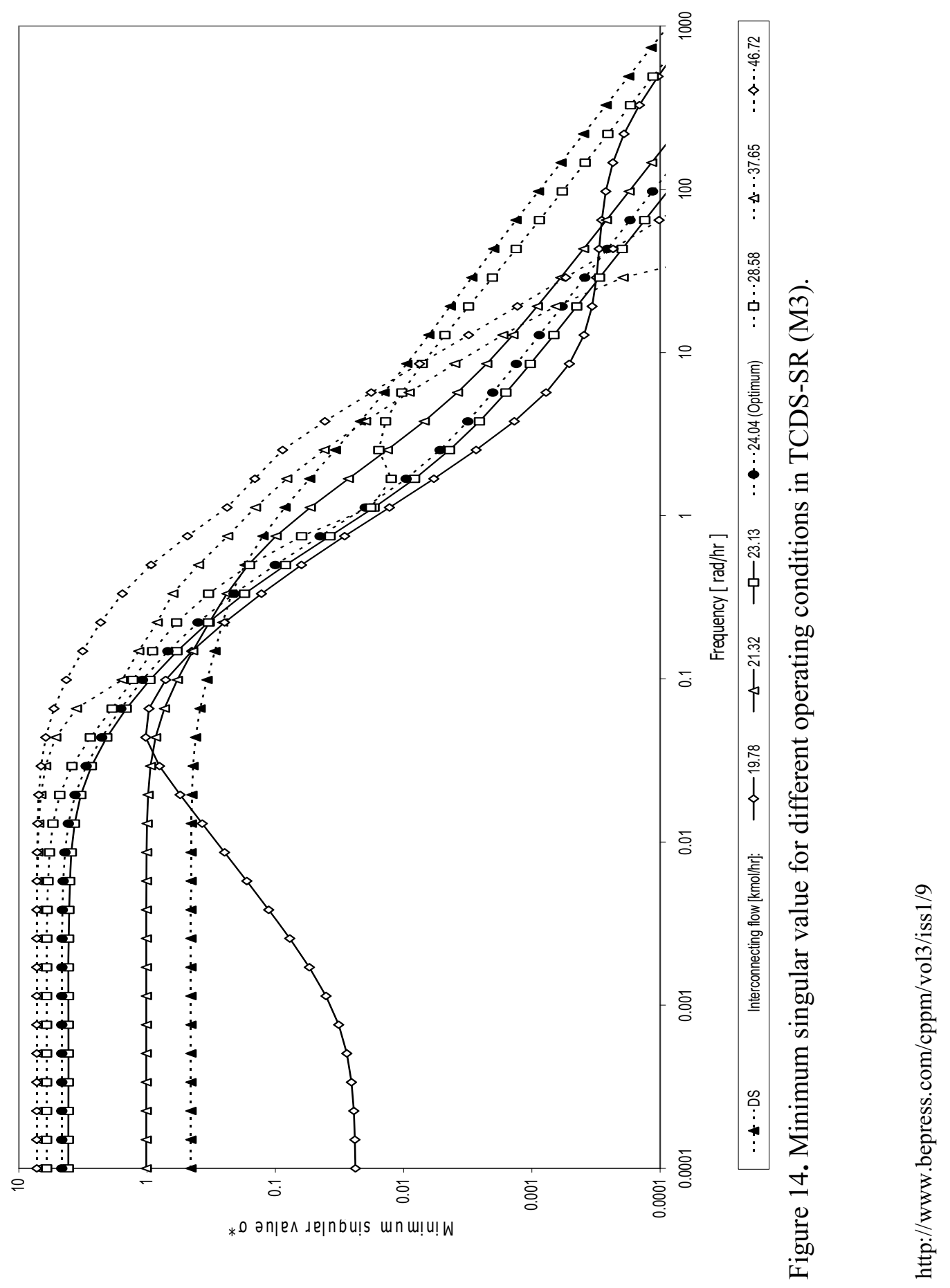




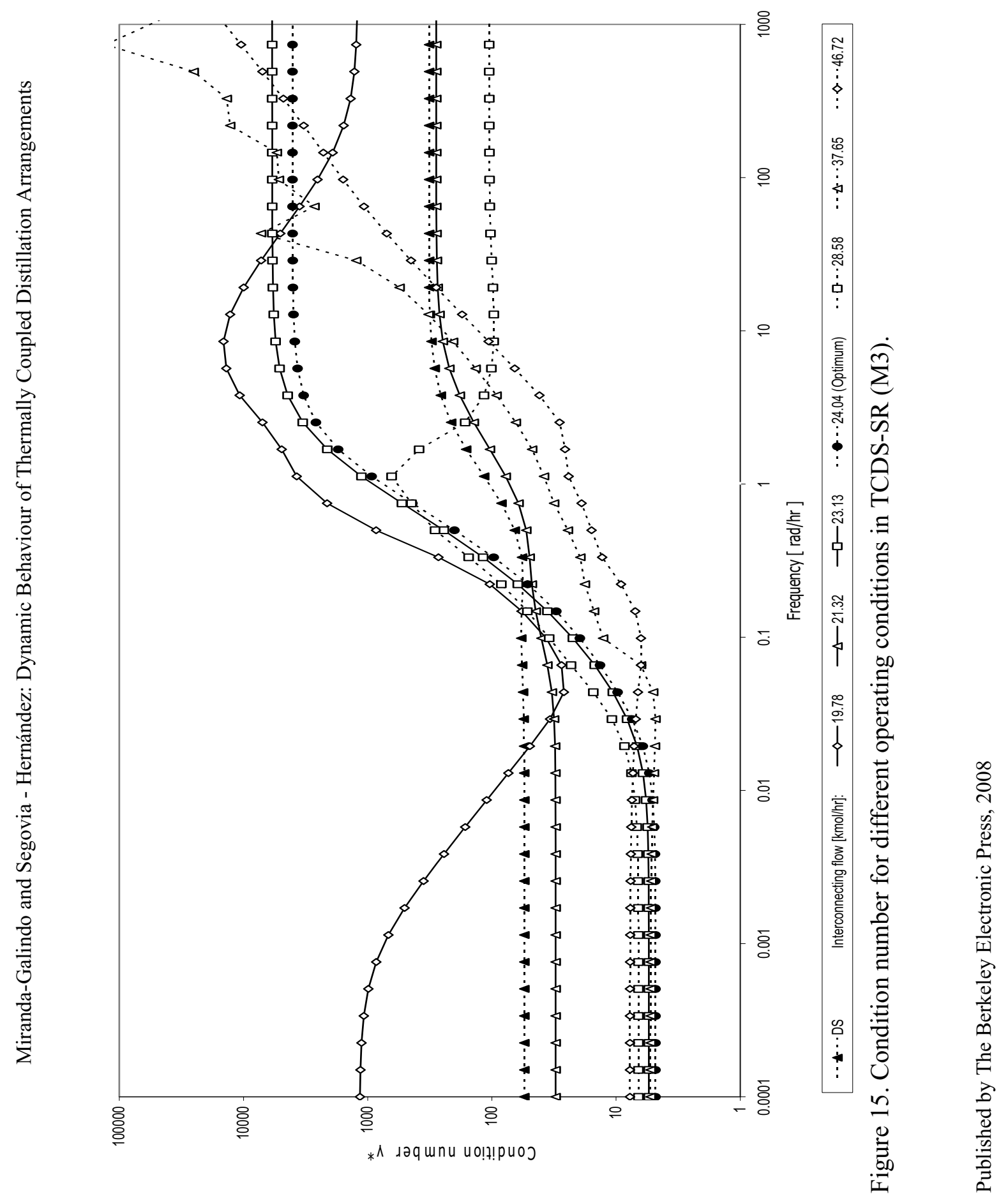




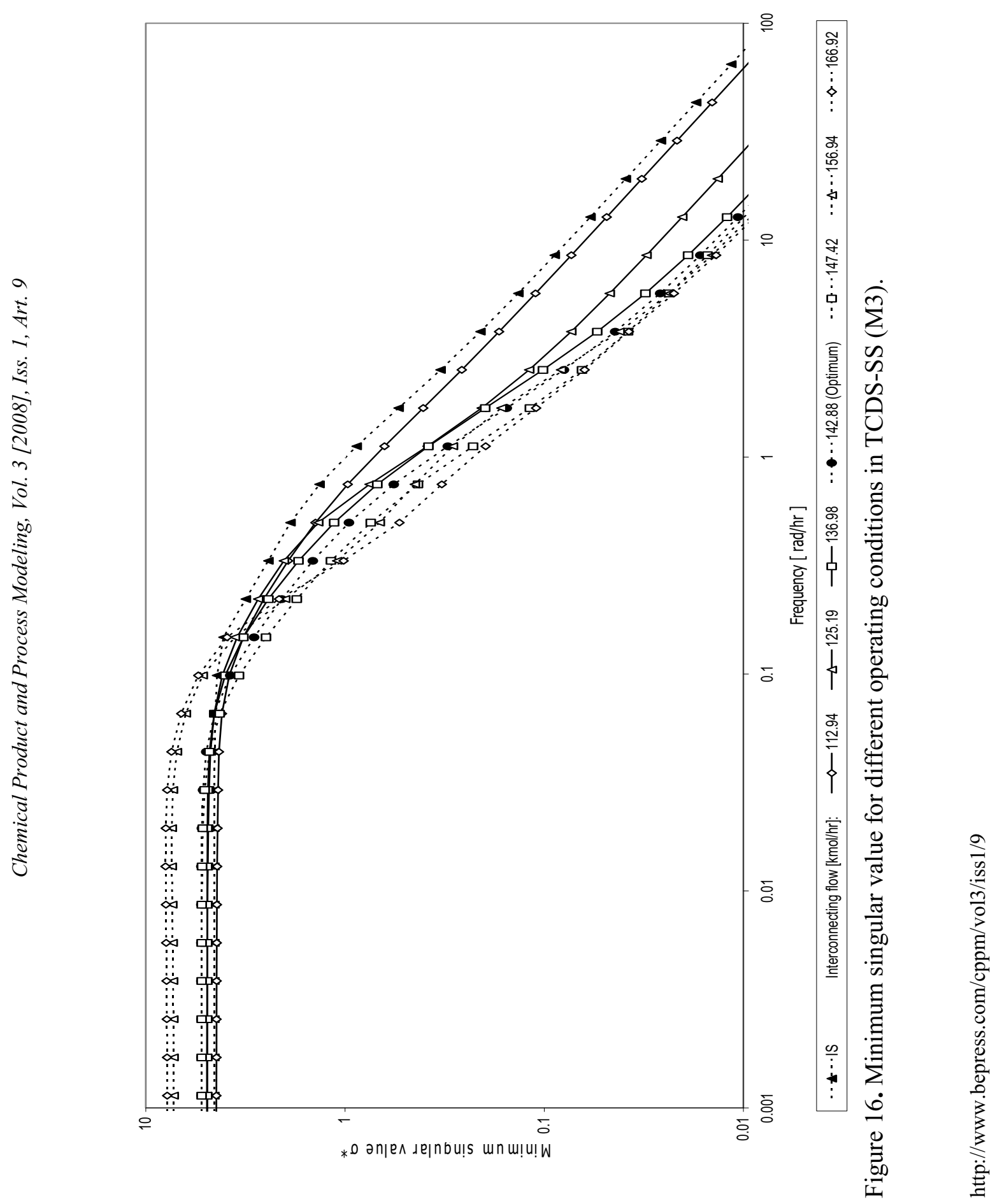




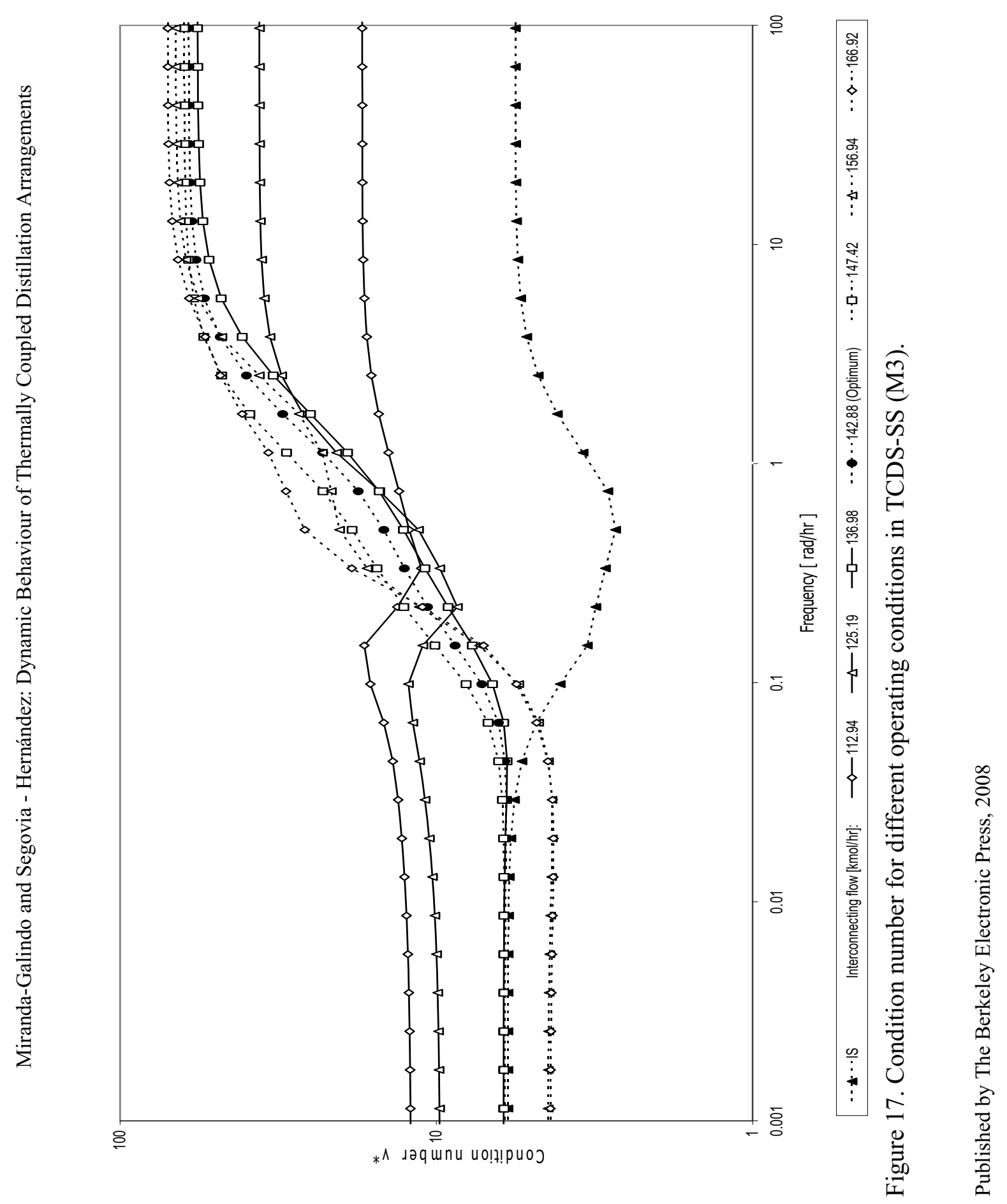


In the Table 5 and Figure 6 , the energy consumption and the $\sigma *$ and $\gamma^{*}$ for the TCDS - SR (M1) are showed. When the arrangement operated at optimal conditions is compared, it can be seen that the TCDS - SS has the lower energy consumption. However, the optimal arrangement has bad control properties. In the case of nonoptimal conditions $(\mathrm{FL}=24.04 \mathrm{kmol} / \mathrm{hr}$; see Table 6) the scheme has better control properties (Figure 8 and Figure 9). The nonoptimal complex schemes show higher values of the minimum singular value and offer the best values in the condition number. Therefore, it can be expected that these coupled systems exhibit better control properties than the optimal sequences under feedback control and it can be expected that system are better conditioned to the effect of disturbances than the optimal arrangements. Those are very important results that show how a convenient operation point (not necessarily the optimal condition) with low energy consumption and good controllability can be chosen. Similar results are showed for TCDS - SS (M2 and M3) in the Table 7 and Figures 12,13, 16 and 17 . One more time, the reboiler duty is lower than the conventional sequence (Table 6 and 7) in the case when the controllability parameters are better than the optimal scheme.

\section{Conclusions}

Upon analysis of the SVD and dynamic simulations, the controllability of TCDS - SR and TCDS - SS in different operating conditions are compared for a given separation problem. Through an optimization procedure, the reboiler duty of the complex arrangements is minimized. At optimal operation, the TCDS controllability is worse than the controllability in nonoptimal conditions (not minimized reboiler duty). However, the TCDS operating at nonoptimal conditions, their controllability is much better. In general, the result is very important because it indicates that TCDS with side column operated at some nonoptimal operating conditions have the best controllability and the lower energy consumption in comparison with conventional distillation sequences and the same complex sequences at optimal operation.

\section{Nomenclature}

$\mathrm{G}=$ transfer function matrix

$\mathrm{FL}=$ interconnecting liquid flow $(\mathrm{kmol} / \mathrm{hr})$

$\mathrm{FV}=$ interconnecting vapor flow $(\mathrm{kmol} / \mathrm{hr})$

$\mathrm{Q}=$ Reboiler heat duty $(\mathrm{kW})$ 
Greek Symbols

$\sigma^{*}=$ maximum singular value

$\sigma_{*}=$ minimum singular value

$\gamma^{*}=$ condition number

\section{References}

Abad - Zarate, E. F., Segovia - Hernández, J.G., Hernández, S., Uribe - Ramírez, A. R., 2006, A Short Note on Steady State Behavior of a Petlyuk Distillation Column by Using a Nonequilibrium Stage Model, The Can. J. Chem. Eng., 84, 381.

Abdul-Mutalib, M. I., and Smith, R. 1998. Operation and Control of Dividing Wall Distillation Columns. Part I: Degrees of Freedom and Dynamic Simulation, Trans Inst. Chem. Eng., 76, 308.

Alcántara - Ávila, R., Cabrera - Ruiz, J., Tamayo - Galván, V.E., Segovia Hernández, J.G., Hernández, S., 2006, Control Properties of Alternative Schemes to Thermally Coupled Distillation Columns for Ternary Mixtures Separation, In Distillation and Absorption '06, IChemeE Symp. Series No. 152, Edited by Eva Sorensen (ISBN: 10085295505 7), UK, 610.

Amminudin, K. A., Smith, R., Thong, D. Y.-C. and Towler, G.P., 2001., Design and Optimization of Fully Thermally Coupled Distillation Columns. Part I: Preliminary Design and Optimization Methodology, Trans Inst. Chem. Eng., 79, 701.

Annakou, O., and Mizsey, P., 1996, Rigorous Comparative Study of Energy Integrated Distillation Schemes, Ind. Eng. Chem. Res., 35, 1877.

Berber, R., and Karadurmus, E., 1989, Dynamic Simulation of a Distillation Column Separating a Multicomponent Mixture, Chem. Eng. Comm., 84, 113.

Dünnebier, G., and Pantelides, C., 1999, Optimal Design of Thermally Coupled Distillation Columns, Ind. Eng. Chem. Res. 38, 162.

Flores, O. A., Cárdenas, J.C., Hernández, S., and Rico - Ramírez, V., 2003, Thermodynamic Analyisis of Thermally Coupled Distillation Sequences, Ind. Eng. Chem. Res., 42, 5940. 
Fidkowski, Z., and Krolikowski, L., 1990. Energy Requirements of Nonconventional Distillation Systems, AIChE J., 36, 1275.

Finn, A., 1993, Consider Thermally Coupled Distillation, Chem. Eng. Prog., October, 41-45.

Hernández, S., and Jiménez, A., 1996, Design of Optimal Thermally - Coupled Distillation Systems Using a Dynamic Model, Trans IChemE, 74, 357.

Hernández, S., and Jiménez, A., 1999a, Design of Energy - Efficient Petlyuk Systems, Comput. Chem. Eng., 23, 1005.

Hernández, S., and Jiménez, A. 1999b. Controllability Analysis of Thermally Coupled Distillation Systems, Ind. Eng. Chem. Res., 38, 3957.

Hernández, S., Pereira-Pech, S., Jiménez, A., and Rico-Ramírez, V., 2003, Energy Efficiency of an Indirect Thermally Coupled Distillation Sequence. The Can. J. Chem. Eng., 2003; 81,1087.

Hernández, S., Segovia - Hernández, J.G., and Rico - Ramírez, V., 2006, Thermodynamically Equivalent Distillation Schemes to the Petlyuk Column for Ternary Mixtures, Energy, 31, 1840.

Hernández - Gaona, C.G., Cárdenas, J.C., Segovia - Hernández, J.G., Hernández, S., and Rico - Ramírez, V., 2005, Second Law Analysis of Conventional and Non Conventional Distillation Sequences, Chem. Biochem. Eng. Q. J., 19, 235.

Jiménez, A., Hernández, S., Montoy, F. A., and Zavala-García, M., 2001, Analysis of Control Properties of Conventional and Nonconventional Distillation Sequences, Ind. Eng. Chem. Res., 40, 3757.

Kaibel, B., Jansen, H., Zich, E., and Olujic, Z., 2006, Unfixed Dividing Wall Technology for Packed and Tray Distillation Columns, In Distillation and Absorption '06, IChemeE Symp. Series No. 15, 252.

Klema, V.C., and Laub, A. J., The Singular Value Decomposition: its Computation and Some Applications, IEEE Transactions on Automatic Control, $25,164$. 
Muralikrishna, K., Madhavan, K.P., and Shah, S.S., 2002, Development of Dividing Wall Distillation Column Design Space for a Specified Separation, Trans Inst. Chem. Eng., 80, 155.

Segovia - Hernández, J.G., Hernández, S., and Jiménez, A., 2002a, Control Behaviour of Thermally Coupled Distillation Sequences, Trans Inst. Chem. Eng., $80,783$.

Segovia - Hernández, J.G.,Hernández, S., Jiménez, A., 2002b, Análisis Dinámico de Secuencias de Destilación Térmicamente Acopladas, Información Tecnológica, 13, 103.

Segovia - Hernández, J.G., Hernández, S., Rico - Ramírez V., and Jiménez, A., 2004, A Comparison of the Feedback Control Behavior between Thermally Coupled and Conventional Distillation Schemes, Comput. Chem. Eng., 28, 811.

Segovia - Hernández, J.G., Hernández, S., and Jiménez, A., 2005a, Analysis of Dynamic Properties of Alternative Sequences to the Petlyuk Column, Comput. Chem. Eng., 29, 1389.

Segovia - Hernández, J.G., Hernández, S., Jiménez, A., and Femat, R., 2005b, Dynamic Behavior and Control of the Petlyuk Scheme Via a Proportional Integral Controller with Disturbance Estimation, Chem. Biochem. Eng. Q. J., 19, 243.

Segovia - Hernández, J.G., Hernández - Vargas, E.A., Márquez - Muñoz, J.A., Hernández, S., and Jiménez, A., 2005c, Control Properties and Thermodynamic Analysis of Two Alternatives to Thermally Coupled Distillation Systems with Side Columns, Chem. Biochem. Eng. Q. J., 19, 325.

Segovia - Hernández, J.G., Hernández, S., Jiménez, A., 2006a, A Short Note about Energy-efficiency Performance of Thermally Coupled Distillation Sequences, The Can. J. Chem. Eng., 84, 139.

Segovia - Hernández, J.G., Bonilla - Petriciolet, A., Salcedo - Estrada, L.I., 2006b, Dynamic Analysis of Thermally Coupled Distillation Sequences with Unidirectional flows for the Separation of Ternary Mixtures, Korean J. Chem. Eng., 23, 689. 
Segovia - Hernández, J.G.,. Hernández - Vargas, E.A., Márquez - Muñoz, J.A., 2007a, Control Properties of Thermally Coupled Distillation Sequences for Different Operating Conditions, Comput. Chem. Eng., 31, 867.

Segovia - Hernández, J.G., Hernández, S., Femat, R., Jiménez, A., 2007b, Control of Thermally Coupled Distillation Sequences with Dynamic Estimation of Load Disturbances, Ind. Eng. Chem. Res., 46, 546.

Serra, M., Espuña, A., and Puigjaner, L., 1999, Control and Optimization of the Divided Wall Column, Chem. Eng. Process., 38, 549.

Serra, M., Perrier, M., Espuña, A., and Puigjaner, L., 2001, Analysis of Different Control Possibilities Feedback Diagonal and Dynamic Matrix Control, Comput. Chem. Eng.,25, 859.

Serra, M., Espuña, A., and Puigjaner, L., 2003, Controllability of Different Multicomponent Distillation Arrangements, Ind. Eng. Chem. Res., 42, 1773.

Tedder, D. W., and Rudd, D. F., 1978, Parametric Studies in Industrial Distillation: Part I. Design Comparisons, AIChE J, 24, 303.

Triantafyllou, C., and Smith, R., 1992, The Design and Optimization of Fully Thermally Coupled Distillation Columns, Trans Inst. Chem. Eng., 70, 118.

Wolff, E. A., and Skogestad, S., 1995. Operation of Integrated Three - Product (Petlyuk) Distillation Columns, Ind. Eng. Chem. Res., 34, 2094.

Yeomans, H. and Grossmann, I., 2000, Optimal Design of Complex Distillation Columns Using Rigorous Tray - by - Tray Disjunctive Programming Models, Ind. Eng. Chem. Res., 39, 4326. 